\title{
Research on New Development of Hand-drawn Animation in New Media
}

\section{Era}

\author{
Qian Wang ${ }^{1, a}$ \\ ${ }^{1}$ Guangdong Polytechnic, Foshan, Guangdong, China, 528041 \\ ${ }^{a}$ email
}

Keywords: Hand-drawn Animation, New Media Era, New Development

\begin{abstract}
The new media leads to the rapid progress of the animation industry, and brings about the new development of the traditional hand-drawn animation. This paper firstly introduces the concept of new media era and the hand-drawn Animation, and then expounds the new development of hand-drawn Animation made by new media, such as reduce drawing difficulty, enhancing artistic expression, raising transmission speed and produce mutual relationship to provide references for the relative researchers.
\end{abstract}

\section{Concept of New Media Era}

New media is a relative concept, which is a new media form after the traditional media such as newspapers, radio, and television and so on. It includes network media, mobile media, digital TV and so on. New media is a broad concept, the use of digital technology, network technology, through the Internet, broadband local area network, wireless communication network, satellite channels, and computers, mobile phones, digital TV terminal, to the user to provide information and entertainment services form of communication. Strictly speaking, new media should be called digital new media.

First, the new media stresses the integration of voice, video, text information. When you read an article online, you can link to other related articles; some words, terms do not understand from this article. You can to the point that the thesaurus dictionary will tell us its meaning, even demonstrate an animation or music for us to see and hear. But I think it should be just the initial stage of the development of new media, with the development of science and technology, we will get more options of power, and access to the visual, listening, touching, smelling, moving and other multi-faceted experience and enjoyment. Secondly, interactivity is the unique charm of the new media. The era of mass media is increasingly giving way to individuals and participatory media, which will change the media industry and the society as a whole. With the rapid development of the Internet, the influence of the new media based on digital technology has been enhanced, and the impact on the traditional media is also growing. Some experts predict that within the next few years, $\mathrm{TV}$, computer, and may have been integrated, and the media has entered the era of new media.

\section{Concept and Features of Hand-drawn Animation}

Throughout the animation art history, the art form of hand drawn animation has a long history under the new media environment. With the emergence of modern electronic information technology to breed under the new media environment, 3D animation, hand drawn animation and 
stop motion animation art category have emerged. In essence, hand-painted animation was initially as a comprehensive nature of animation art, including many painting category and subject content. The concept of hand-painted animation has been proposed with the difference of 3D animation art form. Based on this, hand drawn animation art maintained its unique artistic form, after the baptism of time, the hand drawn animation art personality characteristics of enduring, generally art form remained unchanged.

Hand drawn the advantage of simple lines can be used to outline the role of the image of the birth place, but can show the inherent nature of the rhythm. This style of drawing requirements more stringent, need to sketch and sketch accurate lines and characterization. Sports and music using colors combination and change of collocation, embodies the aesthetic form of an image flow. This particular form of aesthetics is the unique feature of hand drawn animation. Each animation style is not the same as the shape of the characteristics of hand drawn animation according to the characteristics of the model is divided into: realistic style, comic style. The realistic style is similar to the proportion of real people, proportional relations in a natural object as the reference object, the original object shape structure refining, the main characteristics of outstanding original object, the pursuit of real natural shape design of the basic elements. Hand painted animation and the impact of the development of the birth of the early, the early animation has been painted shooting, is a complex, professional career. Some experimental animation directors have made an indelible contribution to the exploration of the technique.

\section{New Development of Hand-drawn Animation in New Media Era}

Reduce Drawing Difficulty. The real motion simulation of the computer 3D animation technology and the image file of the static frame sequence can completely solve the shortcoming of the camera. We can make action draw more simple and easy to understand and convenient. In animation software, we build models, posts good materials and textures. In accordance with the animation need light source set up the direction of the light of the using dynamics and other animation technology set the animation object. Then generate static frame sequence image file save. Animation drawing personnel in accordance with the generation of static frame sequence image files by drawing a picture can be completed. In traditional hand drawn animation in general will be the first layer of the characters and the background layer on the drawing. This increases the workload that is drawn under the condition of no change in the background of each case repeated drawing, also increased the drawing is not unified video stroboscopic phenomenon is serious, and now most of the computer has a layered overlay function and the principle of image processing software, so the use of computer image processing software layer superposition principle and hierarchical animation making the principle of combining, will the animation storyboard in the background from the moving body layer separate from the line drawing and color rendering, also can be solved in traditional hand drawn animation when each frame to draw the background, so as to reduce the workload but also solve the background of each grid rendering are not uniform and part of a video stroboscope. In the traditional hand-painted animation technology to draw a good re unification, but due to the objective existence of the error cannot be avoided, and the cartoon drawing completed more color is not uniform and cannot avoid the rendering error by more than one person, and has powerful image processing function of computer image processing software, so the use of computer image processing software. Stamp, and other tools, will move in the animated cartoon body line and color scanning after scanning or shooting, shooting and scanning of partial color, line and color rendering personnel due to leakage of pen weight, direction, inconsistent frame 
by frame to adjust and modify the color difference. The manual drawing of the basic unity resolves a part of the video flicker problem.

Enhance Artistic Expression. New media aesthetic unity makes style diversification and individuation cartoon works becomes more and more important. Arts and crafts movement advocated by the 19th century by British Morris and Ruskin is under the pattern of monotone conservative design style and the development and technology arts and crafts movement. Chinese ink animation, paper-cut animation is in order to break the original single line painted a single situation and explore the style to maintain the personality of the national art, in the history of the world animation has left a strong. Traditional hand drawn animation can give people a very warm feeling, and the performance is much exaggerated, very interesting, with a very strong artistic texture. Under the condition of new media technology, the traditional two-dimensional hand drawn animation and technology integration, from the traditional two-dimensional hand drawn animation and learn from rich performance, maverick action rules. Therefore, the current and new media three-dimensional technology integration of hand drawn animation not only retains the traditional hand drawn animation art features, but also the formation of a new three-dimensional sense of the stronger, more personalized features of the personalized space. In the motion rhythm and exaggeration of the hand drawn animation has done a good draw. In order to avoid the animation machinery, inflexible and rigid, simple effect, the combination of media and the new technology hand drawn animation, continue to absorb and learn from the traditional hand drawn animation in the action rhythm and exaggerated the extent of characteristics. Two-dimensional image is light and shadow and full of watercolor texture as well as the paper rough sense. Multimedia technology is changing the concept of animation, the technology life hard and degenerated into flexible artistic style. The animation can reconcile the aesthetic orientation of commercial animation and the vulgarization of mass. The cartoon people and give full play to the imagination, good cartoon is a hauntingly works of art. But no one would like to see those commonplace scene digital effects to make this more exciting. At present, the Chinese animation industry neglects this area. It is necessary to apply the computer image technology in the traditional hand drawn animation in China.

Raise Transmission Speed. Before the advent of new media, such as digital TV, mobile phones, internet and other new media, television and movies are the main media of the spread of animation art. But the film media has its limitations, its freedom is very low, the audience must be in particular location specific screen time to watch a particular film, TV media compared to film and media a little better, it can be in any place where a TV can be free to watch, but it is also limited, is the TV program broadcast time is fixed in the, the audience wants to see must hold that time can be. After the birth of the new media, such as mobile media and Internet media has a very high degree of freedom, the audience can choose what they want to see in the free place and free time. Animation is not only used in the past, but now it is also used in mobile phone, network and other new carriers. Animation art combined with the new media, its application quickly expanded to various fields, also produced a variety of animation. These new media animation art form, so that they can be free from work and other factors, to find fun, from easy perceptual level pleasure people's senses the pleasure, to eliminate and reduce pressure, make body and mind to relax. But whether it is a mobile phone media or network media or new media era of animation based on the characteristics of these different media, in terms of content, details, color and length, and so on, it needs to do some adjustments. In the production of different media animation content should be treated according to the different characteristics of the media. It can be predicted that the animation will continuously enhance its vitality with the progress of technology. 
Produce Mutual Relationship. All the work released in the film is solidified in the hard carrier, such as the video or curing. The audience can only be satisfied with the quiet acceptance and appreciation. The new media animation is different from the traditional animation. One of the most obvious characteristic is that the new media animation has a stronger interaction. The relationship between traditional animation and the viewer is the receiver and the giver. After the entry into the era of new media animation, the relationship between the two broke and be accepted the fixed pattern, but the viewer into the, people no longer single use eyes to see, but by the whole people to interact with. A cell phone game requires the player to finger on the screen slide to cut off one appeared on the screen in fruit, with fruit, frequency more and more quickly, the player's finger sliding speed is also growing fast, the players fit into the game animation, and generate interactive relationship, experience the fun of game animation. The extent of the interaction between the new media and the audience is not determined by the breadth of the media coverage, but the depth of the new media use. New media animation is to break the one-way transmission pattern of traditional animation. The audience can understand the information and master the initiative through the new media platform. Whether it is a single electronic publications, electronic publications network or network animation mobile game, it can be free to choose. The instant download and upload of hand-drawn animation in new media era makes the communication become freer and funnier.

\section{Conclusion}

Hand-drawn animation has experienced more than 100 years from being born. In the new media era, the hand-drawn animation and the digital animation will coexist for a long time. We should strengthen the integration of new media technology and hand-drawn animation according to the features of hand drawn animation to search for a broader road for the new development of hand-drawn animation in the new media era.

\section{References}

[1] Tian Mingxing, Art and Design, Vol. 12 (2014) No 8, p.80-82

[2] Li Jianbo, Appreciation, Vol. 5 (2015) No 5, p.101

[3] Nie Xinru, Journal of Shanghai University (Social Sciences), Vol. 18 (2011) No 3, p.29-35

[4] Ding Ying, Packaging Journal, Vol. 3 (2011) No 3, p.75-78 